\title{
Investigation of the Disintegration Behavior of Dietary Supplements in Different Beverages
}

\author{
Jieyu Zuo, Yuan Gao, May Almukainzi, and Raimar Löbenberg* \\ e-mail: raimar.loebenberg@ualberta.ca \\ Faculty of Pharmacy and Pharmaceutical Sciences, University of Alberta, Edmonton, Alberta, Canada, T6G 2E1
}

\begin{abstract}
The aims of this study were to assess how different beverages and temperatures impact the disintegration time of commercial dietary supplements. Four commercial tablet products, calcium citrate, Ester-C, Boswellia serrata extract, and cinnamon extract, which are considered vitamin-mineral dosage forms or botanical dosage forms, were tested. As described in USP General Chapter <2040> Disintegration and Dissolution of Dietary Supplements, Apparatus A and Apparatus B with or without disks were used with a two-station disintegration tester. Beakers $(1000 \mathrm{~mL})$ that met the USP $<2040>$ standards were used, and two temperature conditions were tested: $37^{\circ} \mathrm{C}$ and $5{ }^{\circ} \mathrm{C}$. Six different types of beverages, including cola, orange juice, and $5 \%, 10 \%, 20 \%$, and $40 \%$ alcohol, were compared against water. Boswellia serrata extract failed to disintegrate. With the exception of $5 \%$ alcohol, all beverages had a significant effect on the disintegration time of calcium citrate and Ester-C. Only cola, orange juice, and $40 \%$ alcohol significantly influenced the disintegration time of the cinnamon extract. The temperature of the immersion media did not affect all of the tested products. The tested beverages should not be used to replace water when ingesting therapeutic products.
\end{abstract}

KEYWORDS: Disintegration, beverage, dietary supplement.

\section{INTRODUCTION}

D isintegration is a prerequisite for dissolution of immediate-release oral dosage forms. The disintegration test is often used to determine whether tablets or capsules disintegrate within the desired time when placed into a liquid medium at given experimental conditions $(1,2)$. This test is a useful tool for quality control and can be a critical parameter for drug release in certain scenarios like highly soluble drugs $(3,4)$. However, disintegration is not a universal surrogate for dissolution as shown in the 1970s for drugs like digoxin. At that time, disintegration was the only required performance test for oral solid dosage forms. Several studies showed that tablets with similar disintegration times failed bioequivalence tests due to different dissolution behaviors of the drug $(5,6)$. However, these early studies showed the value of disintegration and dissolution testing.

Dietary supplements that contain a specific dietary ingredient or ingredients are designed to supplement the diet and enhance nutritional supply. Dietary supplements may include vitamins, minerals, herbs or other botanicals, amino acids, and substances such as enzymes, organ tissues, glandular tissues, metabolites, or probiotics (7).

United States Pharmacopeia (USP) General Chapter $<2040>$ is devoted to dietary supplements, and it divides dietary supplement dosage forms into three categories: vitamin-mineral dosage forms, botanical dosage forms, and other dosage forms (1). The products used in this project included vitamin-mineral dosage forms and botanical dosage forms. The only difference between these two dosage forms is in the use or omission of disks for the disintegration tests (1). Previous studies conducted

*Corresponding author. by Almukainzi et al. (8) and Schmid et al.(9) found that the disintegration time was sensitive to the change of the disintegration apparatus conditions. Both studies contributed to the update of USP General Chapter $<2040\rangle$.

Due to the variety of the excipients and the formulation procedures, different disintegration phenomena may be observed for various dietary supplements. This may lead to differences in the bioavailability of the active ingredients. However, very few comprehensive studies are available that show the bioavailability of dietary supplements linked to the biopharmaceutical properties of the dosage form. From a scientific point of view, it is clear that the contents of a dosage form can dissolve and get absorbed to be bioavailable only if it disintegrates. Therefore, disintegration is the most basic step to ensure bioavailability, but as mentioned before, it is not a universal surrogate for bioavailability.

It is well established that drugs should be taken with a glass of water, while many dietary supplements do not give any further instructions except for the units per serving. No beverage (e.g., water) is specified, and it can be assumed that any available beverage, including pop, juices, and alcoholic beverages, might be used for the administration of dietary supplement dosage forms.

The aim of this study was to investigate the impact of beverages, particularly beverages containing different concentrations of alcohol, on the disintegration time of commercially available dietary supplements and to evaluate the effect of beverage temperature on the disintegration behaviors.

\section{MATERIALS AND METHODS Materials}

This study investigated the influence of beverages on the three commercial tablets: calcium citrate (Kirkland, 
Lot\# 398597-01, exp. 09/14), Ester-C (American Health, Lot\# 306041-01, exp. 11/13), Boswellia serrata extract (The Vitamin Shoppe, Lot\# 121674, exp. 05/15), and cinnamon extract (The Vitamin Shoppe, Lot\# 108010, exp. 08/13).

\section{Media}

All tests were performed with six test beverages including alcoholic beverages, regular Pepsi-Cola, and orange juice (Minute Maid) compared with water, which is the USP reference medium for tablets. The alcoholic beverages were prepared by diluting $95 \%$ ethanol to different concentrations $(40 \%, 20 \%, 10 \%$, and $5 \%)$ to mimic commercial spirits (liquor, wine, and beer). The tests were performed in $750 \mathrm{~mL}$ of the various liquids with six units.

\section{Methods}

A disintegration tester (model ED-2 L, Electrolab, Betatek, Ontario) was used with Apparatus A without disks for botanical tablets smaller than $18 \mathrm{~mm}$ and Apparatus $B$ with disks for vitamin-mineral tablets larger than $18 \mathrm{~mm}$ (2). Beakers (1000 mL) with an inside diameter of $102 \pm 0.5$ $\mathrm{mm}$ (PYREX, No. 1003) were used, satisfying the USP beaker specification for disintegration in Chapter $<701>$, which states that the inside diameter of beakers should range from 97 to $115 \mathrm{~mm}$ when assessing the effects of media on the disintegration time of dosage forms. The evaluated beverage temperatures were $37 \pm 2{ }^{\circ} \mathrm{C}$ (USP) and $5 \pm 1{ }^{\circ} \mathrm{C}$ (simulating a refrigerated beverage) with a bath temperature at $37 \pm 2{ }^{\circ} \mathrm{C}$.

\section{Statistical Analysis}

Individual disintegration times were noted and reported as the mean \pm SD. Minitab was used to perform the statistical analysis. The Bartlett test (normal distribution) was used to test the data that were normally distributed for equal variance. When the conditions of normality and equal variance were met, a one-way ANOVA with an $\alpha$-level of 0.05 was used for the group data analysis. For data with unequal variance, the Kruskal-Wallis rank-sum test was chosen. The independent $t$-test and Mann-Whitney test were used for two-group data analyses with normally distributed data and data with unequal variance, respectively. The statistical tests were conducted between different immersion media or different temperatures in the same immersion medium.

\section{RESULTS}

The study investigated four tablet formulations of dietary supplements: calcium citrate, Ester-C, Boswellia serrata, and cinnamon extract.

The disintegration times of calcium citrate in different buffers at different temperatures are shown in Figure 1A. Both the beverages and the low temperature delayed the disintegration time of the calcium citrate. The mean disintegration times of calcium citrate in different buffers ranged from $1.6 \pm 0.2$ to $6.0 \pm 0.8 \mathrm{~min}$ versus $1.4 \pm 0.2$ min in water at $37^{\circ} \mathrm{C}(p<0.05)$ with the exception of $5 \%$ alcohol $(p=0.092)$. Additionally, low temperature at $5{ }^{\circ} \mathrm{C}$ delayed the mean disintegration times of calcium citrate in all buffers $(p<0.05)$.

The disintegration of the Ester- $C$ tablets differed from that of the calcium citrate tablets. As shown in Figure $1 \mathrm{~B}$, the mean disintegration times of the Ester- $\mathrm{C}$ tablets ranged from $27.6 \pm 2.1 \mathrm{~min}$ in cola to $49.8 \pm 6.4 \mathrm{~min}$ in $40 \%$ alcohol (Figure 1B) compared with $23.4 \pm 1.5 \mathrm{~min}$ in water. The disintegration time was significantly influenced

A

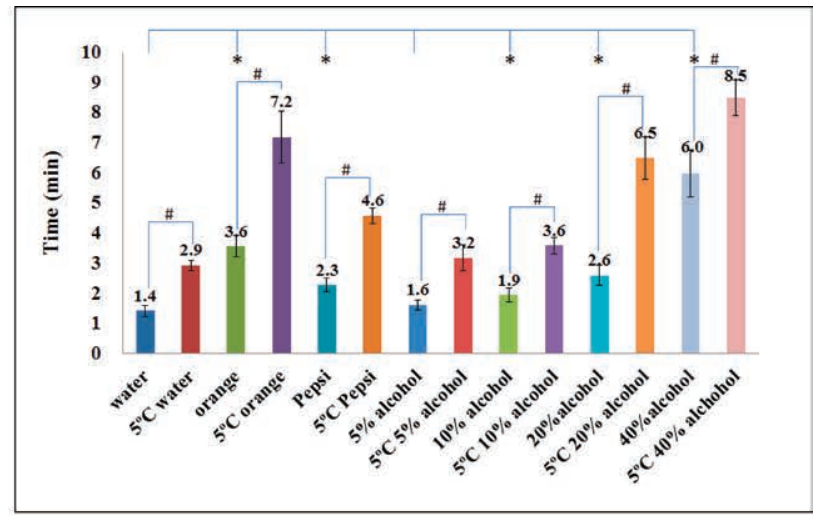

B

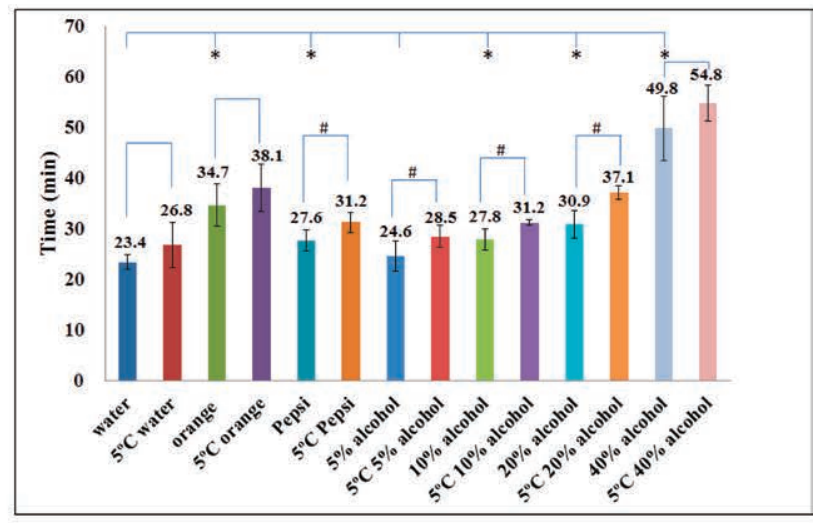

C

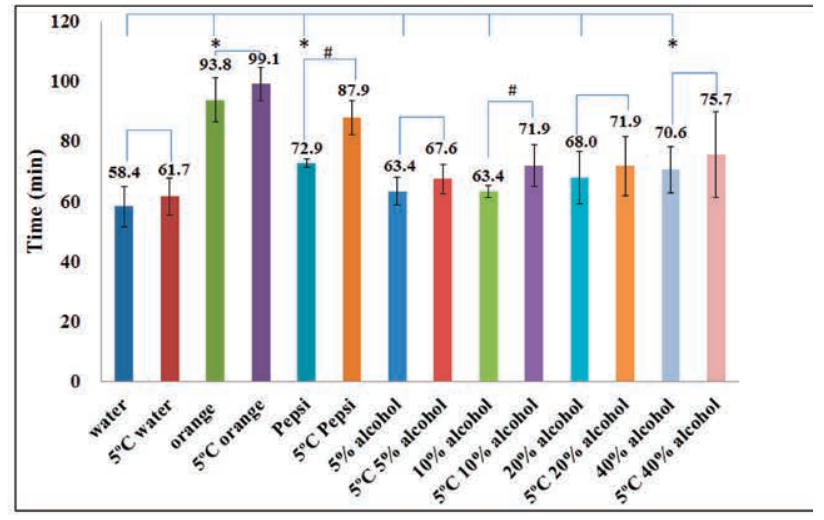

*: significant difference compared to water at $37^{\circ} \mathrm{C}$.

\#: significant difference compared to the same medium at 37 and $5{ }^{\circ} \mathrm{C}$

Figure 1. Disintegration times for (A) calcium citrate, (B) Ester $C$, and (C) cinnamon extract in beverages and water at different temperatures $(n=6)$. 
by the test beverages at the same temperature, with the exception of $5 \%$ alcohol at $37^{\circ} \mathrm{C}(p=0.6889)$. In addition, although temperature had no significant effect on the Ester-C disintegration time in water $(p=0.0927)$, orange juice ( $p=0.2298)$, and $40 \%$ alcohol $(p=0.1735)$, it did significantly affect the disintegration time in the remaining beverages $(p<0.05)$.

Figure $1 \mathrm{C}$ shows the disintegration time of cinnamon tablets in different buffers at different temperatures. Orange juice (93.8 $\pm 7.3 \mathrm{~min})$, cola (72.9 $\pm 1.3 \mathrm{~min})$, and $40 \%$ alcohol (70.6 $\pm 7.8 \mathrm{~min})$ significantly affected the disintegration time of cinnamon tablets when compared with water $(58.4 \pm 6.8 \mathrm{~min})$ at $37^{\circ} \mathrm{C}$, while the other test beverages (5\%, 10\%, and $20 \%$ alcohol) had no significant impact on the disintegration time $(p>0.05)$. In addition, temperature did not influence the disintegration time of cinnamon tablets in the beverages with the exception of cola and $10 \%$ alcohol $(p<0.05)$.

The Boswellia serrata extract tablets did not disintegrate during the 3-h testing period in any of the tested media including water at different temperatures.

\section{DISCUSSION}

Dietary supplements are regulated differently in different regions of the world. For instance, they are regulated as Natural Health Products (NHP) in Canada, and disintegration is the only required performance test according to the Natural Health Product Regulation for immediaterelease dosage forms (10). Dietary supplements are regulated as foods in the United States, and the FDA guidance does not require performance testing (11). The use of dietary supplements has increased over the years. In the United States, $49 \%$ of the population ingests a dietary supplement on a daily basis (12), while $73 \%$ of Canadians regularly take NHPs according to a survey in 2010 (13).

Previous studies showed that the disintegration test can be a valuable performance test for oral dosage forms (4); however, the apparatus setup and the volume of the immersion medium must be considered because they impact the test results $(8,9)$. It is further well established that oral solid dosage forms of drugs should be taken with $250 \mathrm{~mL}$ of water (14). However, a study showed that most patients do not follow this recommendation when they take medications such as capsules and tablets. A study by Fuchs (15) showed that the average water intake for oral drug administration is $115 \mathrm{~mL} ; 15.4 \%$ of patients took less than $60 \mathrm{~mL}, 20.6 \%$ between 61 and $100 \mathrm{~mL}$, and the remaining 64\% more than $101 \mathrm{~mL}$. This behavior indicates poor compliance of patients with the recommendation of $250 \mathrm{~mL}$ for oral drug administration. Extrapolating the lack of compliance to dietary supplements raises the question of what impact the nature of the beverage might have on the disintegration of dietary supplements taken as dosage forms. To our best knowledge, no data is available to answer this question. Therefore, the study investigated different popular beverages and their impact on the disintegration behavior of dietary supplements.
Mechanistically, the first step of the disintegration process is water uptake. A good correlation between the penetration rate of a fluid into a tablet and the disintegration time results from viscosity, contact angle, and surface tension as described by Anwar et al. (16). This relationship can be explained by the Washburn equation (17), which is $v^{2}=\frac{r \gamma \cos \theta t}{2 \eta}$, where $v$ is the volume of liquid penetrating at time $t, \gamma$ is the surface tension, $\theta$ is the contact angle, $\eta$ is the viscosity, and $r$ is the capillary radius. Increasing media viscosity has been shown to cause a profound delay of drug disintegration time (16). Radwan et al. (18), Chuong et al. $(19,20)$, and Kalantzi et al. (21) have shown that product disintegration is delayed in milk. The penetration rates for milk are also slow, which may be a reflection of its relatively high viscosity and low surface tension (16). The viscosity of orange juice is $4.9 \mathrm{MPa} \cdot \mathrm{s}$, whereas the viscosity of water is $1.0 \mathrm{MPa} \cdot \mathrm{s}$ at $20^{\circ} \mathrm{C}(22)$. At $25^{\circ} \mathrm{C}$, the viscosities of ethanol and water are 1.074 and $0.89 \mathrm{MPa} \cdot \mathrm{s}$, respectively (23). However, for most liquids, viscosity increases with decreasing temperature (23). Therefore, the delay in the disintegration time caused by the test beverages in our study may be associated with those factors.

Although the impact of the beverages on the disintegration time of tablets that disintegrate in a short time was statistically significant, these results may not have a major clinical impact because their disintegration times were less than 15 min, which is the average gastric emptying time when fluid is taken with a dosage form in the absence of food (24). However, for tablets that disintegrate slowly, the results may have clinical relevance because of a significant increase in disintegration time (up to 35.4 min), which was observed between water and other beverages. While this study did not investigate bioavailability, it is obvious that a delay in disintegration will result in a delayed dissolution and absorption and consequently will affect bioavailability.

This study only focused on the effect of the beverages on the disintegration time of the dietary supplements.

\section{CONCLUSIONS}

Disintegration is the most basic process that is required for the release of the contents of a dosage form into the body. The results of this study suggest that water may be the best beverage to be used for the administration of dietary supplements and that cola, orange juice, and high alcoholic beverages should be avoided due to their impact on the disintegration of dosage forms. The increasing use of dietary supplements and their different regulatory status in different regions of the world make it necessary to implement appropriate performance testing for these products. However, further studies on the interaction between beverages and dietary supplement are warranted.

\section{ACKNOWLEDGMENTS}

The authors want to thank the United States Pharmacopeial Convention for the support of this study. 


\section{REFERENCES}

1. <2040> Disintegration and Dissolution of Dietary Supplements. In The United States Pharmacopeia and National Formulary USP 36-NF 31; The United States Pharmacopeial Convention, Inc.: Rockville, MD, 2013; pp 1111-1116.

2. $<701>$ Disintegration. In The United States Pharmacopeia and National Formulary USP 36-NF 31; The United States Pharmacopeial Convention, Inc.: Rockville, MD, 2013; pp 305-306.

3. Donauer, N.; Löbenberg, R. A mini review of scientific and pharmacopeial requirements for the disintegration test. Int. J. Pharm. 2007, 345 (1-2), 2-8. DOI:10.1016/j. ijpharm.2007.08.045.

4. Klute, A. S. Disintegration Testing: Strategy for Quality Control Testing of Immediate Release Dosage Forms in Exploratory Development. Am. Pharm. Rev. 2009, 12 (5), 90-93.

5. Fraser, E. J.; Leach, R. H.; Poston, J. W. Bioavailability of digoxin. Lancet. 1972, 300 (7776), 541.

6. Fraser, E. J.; Leach, R. H.; Poston, J. W.; Bold, A. M.; Culank, L. S.; Lipede, A. B. Dissolution and bioavailability of digoxin tablets. J. Pharm. Pharmacol. 1973, 25 (12), 968-973. DOI: 10.1111/j.2042-7158.1973. tb09988.x.

7. Dietary Supplement Health and Education Act of 1994 (DSHEA); Public Law 103-417, Office of Dietary Supplements, National Institutes of Health, U.S. Government Printing Office: Washington, DC, 1994.

8. Almukainzi, M.; Salehi, M.; Bou-Chacra, N. A.; Löbenberg, $\mathrm{R}$. Investigation of the Performance of the Disintegration Test for Dietary Supplements. AAPS J. 2010, 12 (4), 602607. DOI: 10.1208/s12248-010-9221-1.

9. Schmid, K.; Löbenberg, R. Influence of the Changed USP Specifications on Disintegration Test Performance. Dissolution Technol. 2010, 17 (1), 6-10.

10. Natural Health Products Regulations; SOR/2003-196. Justice Laws Website; Minister of Justice, Canada, 2013. http://laws-lois.justice.gc.ca/eng/regulations/ SOR-2003-196 (accessed Sept 25, 2013).

11. Dietary Supplements: New Dietary Ingredient Notifications and Related Issues; Draft Guidance for Industry; U.S. Department of Health and Human Services, Food and Drug Administration, Center for Food Safety and Applied Nutrition (CFSAN), U.S. Government Printing Office: Washington, DC, 2011. http://www.fda.gov/Food/GuidanceRegulation/ GuidanceDocumentsRegulatorylnformation/ DietarySupplements/ucm257563.htm (accessed Sept 25, 2013).

12. Bailey, R. L.; Gahche, J. J.; Lentino, C. V.; Dwyer, J. T.; Engel, J. S.; Thomas, P. R.; Betz, J. M.; Sempos, C. T.; Picciano, M. F. Dietary Supplement Use in the United
States, 2003-2006. J. Nutr. 2011, 141 (2), 261-266. DOI: 10.3945/jn.110.133025.

13. Natural Health Product Tracking Survey-2010 Final Report; Natural Health Products Directorate (NHPD), Health Canada, 2011. http://epe.lacbac.gc.ca/100/200/301/pwgsc-tpsgc/por-ef/ health/2011/135-09/report.pdf (accessed Sept 25, 2013).

14. Waiver of In Vivo Bioavailability and Bioequivalence Studies for Immediate-Release Solid Oral Dosage Forms Based on a Biopharmaceutics Classification System; Guidance for Industry; U.S. Department of Health and Human Services, Food and Drug Administration, Center for Drug Evaluation and Research (CDER), U.S. Government Printing Office: Washington, DC, 2000.

15. Fuchs, J. The amount of liquid patients use to take tablets or capsules. Pharm. Pract. 2009, 7 (3), 170-174.

16. Anwar, S.; Fell, J. T.; Dickinson, P. A. An investigation of the disintegration of tablets in biorelevant media. Int. J. Pharm. 2005, 290 (1-2), 121-127.

17. Washburn, E. W. The Dynamics of Capillary Flow. Phys. Rev. 1921, 17 (3), 273-283. DOI: 10.1103/ PhysRev.17.273.

18. Radwan, A.; Amidon, G. L.; Langguth, P. Mechanistic investigation of food effect on disintegration and dissolution of BCS class III compound solid formulations: the importance of viscosity. Biopharm. Drug Dispos. 2012, 33 (7), 403-416. DOI: 10.1002/bdd.1798.

19. Chuong, M. C.; Poirier, B.; Crosby, S. J.; Pidgeon, C. A modified USP disintegration method to simulate a tablet disintegrated in the stomach when taken with cold beverage or with food. AAPS J. 2007, 9 (S2), 1687.

20. Chuong, M. C.; Taglieri, C. A.; Crosby, S. J.; Ferullo, J. W.; $\mathrm{Ng}, \mathrm{P}$. Effect of Beverages on the In Vitro Disintegration of Immediate-Release Pain Medications. Dissolution Techonol. 2010, 17 (1), 31-37.

21. Kalantzi, L.; Polentarutti, B.; Albery, T.; Laitmer, D.; Abrahamsson, B.; Dressman, J.; Reppas, C. The delayed dissolution of paracetamol products in the canine fed stomach can be predicted in vitro but it does not affect the onset of plasma levels. Int. J. Pharm. 2005, 296 (1-2), 87-93.

22. Stellrecht, P. Comparison of the viscosity of beverages; Application Note Physica Rheometers; Anton Paar Germany Gmbh: Ostfildern, 1999. http://www. bri-advantage.com/instrumentcms/pdf/mcrnote.pdf (accessed Sept 25, 2013).

23. Handbook of Chemistry and Physics, 93rd ed.; Haynes, W. M., Ed.; CRC Press: Boca Raton, FL, 2012.

24. Oberle, R. L.; Chen, T. S.; Lloyd, C.; Barnett, J. L.; Owyang, C.; Meyer, J.; Amidon, G. L. The influence of the interdigestive migrating myoelectric complex on the gastric emptying of liquids. Gastroenterology 1990, 99 (5), 1275-1282. 